\title{
PSYCHIATRIC DISORDERS IN CHILDREN: PATTERN AND CORRELATES AMONG THOSE REPORTING TO A TERTIARY CARE HOSPITAL
}

\author{
Malik Awais Amin, Muhammad Kamran*, Shehzad Rauf, Isbah Gul**, Ahmed Shoaib Tabassum*** \\ Pakistan Naval Ship Shifa Hospital, Karachi Pakistan, *Combined Military Hospital Malir/National University of Medical Sciences (NUMS) Pakistan, **Armed \\ Forces Institute of Mental Health/National University of Medical Sciences (NUMS) Rawalpindi Pakistan, ${ }^{* * *}$ Combined Military Hospital Multan/National \\ University of Medical Sciences (NUMS) Pakistan
}

\begin{abstract}
Objective: To determine the pattern of psychiatric disorders among children reporting to the Psychiatry department Pakistan Naval Ship Shifa Hospital, Karachi.

Study Design: Comparative cross sectional study.

Place and Duration of Study: Psychiatry department Pakistan Naval Ship Shifa Hospital, Karachi, from Feb to Aug 2018.

Methodolgy: A total of 100 children, aged between 6-12 years of age, both male and female, meeting the selection criteria of the study, presenting to the Psychiatry department at Pakistan Naval Ship Shifa Hospital, were enrolled for this study. Informed consent was taken from the parents. The consultant psychiatrist interviewed the patients and diagnosed any psychiatric disorders based on international classification of diseases version 10 . The data was recorded on the study proforma.

Results: Out of a total of 100 children, 66 (66\%) were male, while 34 (34\%) were female. The mean age of the participating children was $8.66 \pm 1.97$ years. The most common psychiatric disorder was attention deficit hyperactivity disorder 44 (44\%), followed by depression 30 (30\%). Other diagnoses included oppositional defiant disorder 12 (12\%), conduct disorder 9 (9\%) and separation anxiety disorder $5(5 \%)$.

Conclusion: Attention deficit hyperactivity disorder and depression are amongst the quite prevalent psychiatric disorders, than that was considered earlier.
\end{abstract}

Keywords: Children, Frequency, International classification of diseases, Mental disorders.

\footnotetext{
This is an Open Access article distributed under the terms of the Creative Commons Attribution License (https://creativecommons.org/licenses/by-nc/4.0/), which permits unrestricted use, distribution, and reproduction in any medium, provided the original work is properly cited.
}

\section{INTRODUCTION}

Psychiatric disorders have been reported to account for as much as $30 \%$ of all the causes of loss of economic productivity and independence among adults globally ${ }^{1}$. The World Health Organization (WHO) estimates suggest that by 2020, depression will become the second leading cause of disability in whole the world ${ }^{2}$.

Literature shows that majority of the psychiatric disorders (between 50-75\%) begin in childhood and adolescence $^{3}$. There is a paucity of literature regarding the psychiatric disorders in middle and low income countries. A systematic review of the psychiatric disorders in middle and low income countries reports early life prevalence rates of between $10-20 \%^{4}$. Large scale studies show that the socioeconomic status, gender and age are found to be significant risk factors in the occurrence of psychiatric disorders. While disruptive disorders and attention deficit and hyperactivity disorder are more commonly found among boys, anxiety disorders are more prevalence among the girls, at the post-pubertal age ${ }^{4}$.

A study on children with intellectual disabilities

Correspondence: Dr Muhammad Kamran, Consultant Psychiatrist, Psychology Department, CMH Malir, Karachi Pakistan

Received: 01 Mar 2019; revised received: 30 Nov 2019; accepted: 01 Dec 2019 found oppositional defiant disorder (ODD) to be the commonest most diagnosis (14\%) followed by ADHD $(10 \%)^{5}$. In a study from Iran (which is Pakistan's bordering neighbor) on the children from general population, the most common diagnosis was ADHD (8.6\%) followed by $\operatorname{ODD}(7.3 \%)^{6}$.

Other international studies have reported much different results from local studies above. A study in Chile conducted on 792 children reported a prevalence of $25.4 \%$ for the psychiatric disorders 7 . The most common diagnosis was ADHD (12.6\%), followed by Separation Anxiety Disorder (10.9\%). In contrast, a Norwegian study on 1250 children reported ADHD as being the most common diagnosis as well, but having a different prevalence of $1.9 \%$ only $^{8}$. A study from China, that employed 19711 children, reported ADHD as the most common diagnosis $(5.37 \%)^{9}$. The diagnoses have varied in different population according to the socioeconomic status, the diagnostic instrument used, age range of the children, family characteristics, gender and the study location ${ }^{10}$.

This study would enhance the already prevailing data and provide the burden of disease in our community. Moreover, it will contribute towards the rationale for informing future health policies at the local level for reforming mental health services in Pakistan. 


\section{METHODOLOGY}

This comparative cross sectional study was conducted at Psy-chiatry department Pakistan Naval Ship (PNS) Shifa Hospital Karachi, from February to August 2018. Sample size ( $n=73$ at least) was calculated by using the WHO sample size calculator, including parameters: $95 \%$ confidence level, $7 \%$ population proportion 5 and precision to be $5 \%$.

Study was approved from the ethics committee of PNS Shifa Hospital Karachi (Approval Certificate no. Psy-3/2018). A total of 100 patients between 6-12 years of age, both male and female, reporting to the Psychiatry department PNS Shifa Hospital Karachi during the study period was taken. These were meeting the selection criteria of the study. They were enrolled in the study through consecutive non-probability sampling after obtaining their informed consent. Data was recorded on study proforma. Those patients with autoimmune disorders, cerebral palsy, tumors of the brain, other neurological disorders and co morbidities including diabetes mellitus, asthma, nephrotic syndrome, hypothyroidism and epilepsy were excluded.

Structured questionnaire was used to collect demographic details. Diagnoses of the cases were done by a consultant psychiatrist using criteria of International Classification of Diseases (ICD 10). Psychiatric diagnosis was noted.

Data analysis was carried out through the use of Statistical Package for Social Sciences (SPSS) version 23. Qualitative variables such as gender, education, marital status and psychiatric diagnosis were noted as the percentages and frequencies. Age and other quantitative variables were described as mean and the standard deviation. Chi squared test was applied post-stratification. The $p$-value of $<0.05$ was considered to be statis-tically significant.

\section{RESULTS}

The mean age of patients was $8.66 \pm 1.97$ years. A total of 53 participants (53\%) were $<9$ years of age, while 47 children (47\%) were from the 9-12 years' age group. The gender distribution of the children showed that there were 66 males (66\%) and 34 females (34\%). A large proportion of the children $30(30 \%)$ had not gone to the school as yet, $38(38 \%)$ were in Montessori class, while $32(32 \%)$ were enrolled in primary classes.

The consultant psychiatrist diagnosed a large number of children as having ADHD $44(44 \%), 12$ $(12 \%)$ had ODD, 9 (9\%) had conduct disorder, 5 (5\%) had SAD, while 30 (30\%) were diagnosed with having depression (figure).

Age was a confounding variable for ADHD, ODD and the depression (table-I \& II). Educational status of children was a confounding variable for ADHD and depression (table-III).

\section{DISCUSSION}

This study set out to determine the pattern of psychiatric disorders among children presenting to the Psychiatry OPD of a tertiary care hospital in Karachi. The highest frequency found was that of ADHD (44\%), followed by $30 \%$ of the patients having the depressive disorders. A total of $12 \%$ patients were diagnosed with ODD, $9 \%$ with conduct disorder, while $5 \%$ of the children were reported having the separation anxiety disorder.

Alavi et al, reported a prevalence rate of $36(4.5 \%)$ for an Iranian cohort of the 799 children $^{6}$. Vicente et al, reported a similar prevalence rate for ADHD (12.6\%) for a sample of 792 children from Chille ${ }^{7}$. Albon et al, carried out a survey asking questions from the 250 Swedish pediatricians. They reported about prevalence rate of $9 \%$ for externalizing disorders such as ADHD. Wichstrom et al, in a study conducted on 1250 Norwegian preschoolers reported $1.9 \%$ prevalence rate for

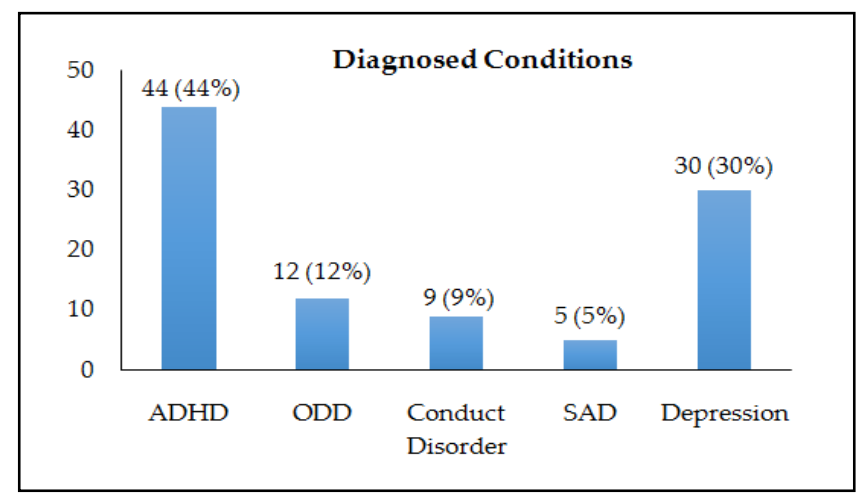

Figure: Pattern of psychiatric disorders in children.

ADHD. These rates are much lower than our study, except for the Separation Anxiety Disorder. A Chinese study from Sichuan province on a sample of 19711 children reported a prevalence rate of $5.37 \%$ for ADHD'. Another Chinese study from the Northeastern China on a sample of 8848 children reported a prevalence rate of $0.84 \%$ for $\mathrm{ADHD}^{3}$. In contrast to all these studies, our study had high prevalence for the ADHD $(44 \%)$. One of the main reasons of this difference is that our study was conducted on patients who were reporting to hospital with some psychiatric presenting complaint. On the other hand, all of these studies except for 
the Iranian study, were conducted on children either going to the school or at home. As far as the Iranian study is concerned, it also reported a higher prevalence rate of ADHD (8.6\%) as compared to other studies. However, our study has a higher reported frequency of ADHD, which is troubling. Some of the reasons for such a high rate may be the poor early life develop- phical locations were quite different from our study. Imran et al, reported 1\% prevalence rate for Conduct Disorder among children with intellectual disabilities in Lahore. The other studies reported a similarly low prevalence rate for the conduct disorder: Alavi et al ${ }^{6}$, 21 (2.6\%); Vicente et $a l^{7}, 2.5 \%$; Qu et $a l^{9}, 1.52 \%$ and Xiaoli et $a l^{3}, 1.52 \%$. Interestingly, Albon et al, reported a

Table-I: Age as an effect modifier in psychiatric disorders in children.

\begin{tabular}{|c|c|c|c|c|c|c|c|c|c|c|}
\hline \multirow[t]{2}{*}{ Age Groups } & \multicolumn{2}{|c|}{$\begin{array}{c}\text { Attention Deficit } \\
\text { Hyperactivity } \\
\text { Disorder, } 44(44 \%)\end{array}$} & \multicolumn{2}{|c|}{$\begin{array}{c}\text { Oppositional } \\
\text { Defiant Disorder } \\
12(12 \%) \\
\end{array}$} & \multicolumn{2}{|c|}{$\begin{array}{c}\text { Conduct } \\
\text { Disorder } \\
9(9 \%)\end{array}$} & \multicolumn{2}{|c|}{$\begin{array}{c}\text { Separation } \\
\text { Anxiety Disorder } \\
5(5 \%)\end{array}$} & \multicolumn{2}{|c|}{$\begin{array}{c}\text { Depression } \\
30(30 \%)\end{array}$} \\
\hline & No. of pts & $\begin{array}{c}p- \\
\text { value }\end{array}$ & $\begin{array}{c}\text { No. of } \\
\text { pts }\end{array}$ & $\begin{array}{c}p \text { - } \\
\text { value }\end{array}$ & $\begin{array}{c}\text { No. of } \\
\text { pts }\end{array}$ & $\begin{array}{c}p- \\
\text { value }\end{array}$ & $\begin{array}{c}\text { No. of } \\
\text { pts }\end{array}$ & $\begin{array}{c}p- \\
\text { value }\end{array}$ & $\begin{array}{c}\text { No. of } \\
\text { pts }\end{array}$ & $\begin{array}{c}p \text { - } \\
\text { value }\end{array}$ \\
\hline $6-8$ yrs $(n=53)$ & 40 & \multirow{2}{*}{$<0.01$} & - & \multirow{2}{*}{$<0.01$} & 3 & \multirow{2}{*}{0.30} & 1 & \multirow{2}{*}{0.15} & 9 & \multirow{2}{*}{$<0.01$} \\
\hline $9-12$ yrs $(n=47)$ & 4 & & 12 & & 6 & & 4 & & 21 & \\
\hline
\end{tabular}

Table-II: Gender as an Effect modifier in psychiatric disorders in children.

\begin{tabular}{|c|c|c|c|c|c|c|c|c|c|c|}
\hline \multirow[t]{2}{*}{ Gender } & \multicolumn{2}{|c|}{$\begin{array}{c}\text { Attention Deficit } \\
\text { Hyperactivity } \\
\text { Disorder, } 44(44 \%)\end{array}$} & \multicolumn{2}{|c|}{$\begin{array}{c}\text { Oppositional } \\
\text { Defiant Disorder } \\
12(12 \%)\end{array}$} & \multicolumn{2}{|c|}{$\begin{array}{c}\text { Conduct } \\
\text { Disorder } \\
9(9 \%) \\
\end{array}$} & \multicolumn{2}{|c|}{$\begin{array}{c}\text { Separation } \\
\text { Anxiety Disorder, } \\
5(5 \%) \\
\end{array}$} & \multicolumn{2}{|c|}{$\begin{array}{c}\text { Depression } \\
30(30 \%)\end{array}$} \\
\hline & No. of pts & $\begin{array}{c}p- \\
\text { value }\end{array}$ & $\begin{array}{c}\text { No. of } \\
\text { pts }\end{array}$ & $\begin{array}{c}p- \\
\text { value }\end{array}$ & $\begin{array}{c}\text { No. of } \\
\text { pts }\end{array}$ & $\begin{array}{c}p \text { - } \\
\text { value }\end{array}$ & $\begin{array}{c}\text { No. of } \\
\text { pts }\end{array}$ & $\begin{array}{c}p- \\
\text { value }\end{array}$ & $\begin{array}{c}\text { No. of } \\
\text { pts }\end{array}$ & $\begin{array}{c}p \text { - } \\
\text { value }\end{array}$ \\
\hline Male $(n=66)$ & 28 & \multirow{2}{*}{0.66} & 09 & \multirow{2}{*}{0.75} & 07 & \multirow{2}{*}{0.71} & 02 & \multirow{2}{*}{0.33} & 20 & \multirow{2}{*}{0.93} \\
\hline Female $(n=34)$ & 16 & & 03 & & 02 & & 03 & & 10 & \\
\hline
\end{tabular}

Table-III: Educational Status as an Effect modifier in psychiatric disorders in children.

\begin{tabular}{|c|c|c|c|c|c|c|c|c|c|c|}
\hline \multirow{2}{*}{$\begin{array}{l}\text { Educational } \\
\text { Status }\end{array}$} & \multicolumn{2}{|c|}{$\begin{array}{c}\text { Attention Deficit } \\
\text { Hyperactivity } \\
\text { Disorder, } 44(44 \%)\end{array}$} & \multicolumn{2}{|c|}{$\begin{array}{c}\text { Oppositional } \\
\text { Defiant Disorder } \\
12(12 \%)\end{array}$} & \multicolumn{2}{|c|}{$\begin{array}{c}\text { Conduct } \\
\text { Disorder, } 9(9 \%)\end{array}$} & \multicolumn{2}{|c|}{$\begin{array}{c}\text { Separation } \\
\text { Anxiety Disorder } \\
5(5 \%)\end{array}$} & \multicolumn{2}{|c|}{$\begin{array}{c}\text { Depression } \\
30(30 \%)\end{array}$} \\
\hline & $\begin{array}{c}\text { No. of } \\
\text { pts }\end{array}$ & $\begin{array}{c}p \text { - } \\
\text { value }\end{array}$ & $\begin{array}{l}\text { No. of } \\
\text { pts }\end{array}$ & $\begin{array}{c}p \text { - } \\
\text { value }\end{array}$ & $\begin{array}{l}\text { No. of } \\
\text { pts }\end{array}$ & $\begin{array}{c}p \text { - } \\
\text { value }\end{array}$ & $\begin{array}{l}\text { No. of } \\
\text { pts }\end{array}$ & $\begin{array}{c}p- \\
\text { value }\end{array}$ & $\begin{array}{l}\text { No. of } \\
\text { pts }\end{array}$ & $\begin{array}{c}p \text { - } \\
\text { value }\end{array}$ \\
\hline Nil $(n=30)$ & 23 & \multirow{3}{*}{$<0.01$} & 03 & \multirow{3}{*}{0.40} & 1 & \multirow{3}{*}{0.46} & - & \multirow{3}{*}{0.07} & 03 & \multirow{3}{*}{0.01} \\
\hline Montessori $(\mathrm{n}=38)$ & 18 & & 03 & & 4 & & 01 & & 12 & \\
\hline Primary $(n=32)$ & 03 & & 06 & & 4 & & 04 & & 15 & \\
\hline
\end{tabular}

ment opportunities available for children with poor nutrition, lack of a clean living environment crowded housing and scarcity of social care and support.

Variations in the prevalence rates for the ODD have been reported in literature. Prevalence rates for ODD similar to our study (12\%) were reported by Imran et $a l^{5}, 14 \%$ and Alavi et al ${ }^{6}, 7.3 \%$. This could possibly be because of similar population demographicsthe Iranian frequency being a little lower due to slightly better socioeconomic conditions there. The rest of the studies found much lower prevalence rates: Vincente et al. 7 (6.4\%), Qu et al. 9 (3.01\%) and Xiaoli et al, 3 $(1.21 \%)$. This can be explained by larger samples taken by these studies as well as much better socioeconomic conditions and early life living conditions.

The prevalence rates of the Conduct Disorder in children as reported by studies from different geogra- similar frequency of children diagnosed with Conduct Disorders at Pediatric clinics in Sweden to than of our sample $(9 \%)^{12}$, One possible explanation could be that Albon et al, presented self-reported frequencies by the Pediatricians. There is a high risk of bias in such selfreported rates and any statistical value presented in this fashion must be treated with caution when generalizing these results to some larger population.

The prevalence of separation anxiety disorder was low in our study (5\%) in comparison other disorders diagnosed. This rate was quite similar to that reported by the Alavi et al ${ }^{6}$, in an Iranian population $(5.9 \%)$, but much lower than the Chilean reported frequency of $7(10.9 \%)$, Interestingly, the prevalence rates of the Separation Anxiety Disorder were much lesser in the Norwegian study (Wichstrom et al. $0.9 \%$ ) and the Chinese studies (Qu et al $0.48 \%{ }^{9}$; Xiaoli et al ${ }^{3}, 0.92 \%$ ) was much lesser than that found in the present study ${ }^{11}$. 
Depression disorders were found to have much higher prevalence rate $(30 \%)$ in our study, when compared to the other studies in the literature. Alavi et $a l^{7}$, reported a prevalence of $4.5 \%$, Wichstrom et al ${ }^{11}, 2 \%$, Qu et $a^{9}, 1.9 \%$ and Xiaoli et al ${ }^{3}, 1.32 \%$.

Multiple limitations were present in the study design, though. It is important to keep the fact ni mind when comparing results of our study with other studies that our study was done on patients reporting to the psychiatry OPD. This tells that all participants had some psychiatric disorder. Prevalence rate of the psy*chiatric disorders was thus $100 \%$ among our cohort. In contrast, Xiaoli et al, Vicente et al, Qu et al, Wichstrom et al, and In-Albon et al, had prevalences of $25.4 \%, 15 \%, 7.1 \%, 15.2 \%$ and $9.49 \%$, respectively $3,7,9,10,11$. Among youth one fourth of population may have a mental disorder during the past year. One third may have mental disorder across their whole lifetimes ${ }^{12}$. One study on preschool children showed that Anxiety disorders were the most frequent conditions in children. These were followed by the behavior disorders, mood disorders, and substance use disorders ${ }^{13}$. The SDQ predictive algorithms are useful for screening at preschool-age; thus to identify children at an increased risk of mental disorders in the preadolescence ${ }^{14}$. Child and adolescent psychiatry is thus very vital to respond to a large number of mental disorders in public, arising early in life ${ }^{15}$. In a study conducted in Canada internalizing, and externalizing symptoms at age 5 years were associated with onset of subsequent mental health conditions between ages 6 and 14 years ${ }^{16}$. A study done in India proved that more than $40 \%$ of the children enter the school system with relative vulnerabilities in social-emotional functioning that are associated with early-onset mental health conditions ${ }^{17}$. Moreover Stigma may present itself as a barrier to the problem recognition because it may impose a significant personal cost on the family, thereby affecting the help-seeking process earlier than considered by previous work ${ }^{18}$. Thus there is a strong explanation for the relatively high prevalence rates of the psychiatric disorders among our population. Another limitation of our study was a small sample size. Also, the study was conducted at a single center. Future studies should incorporate a larger sample size, include multiple centers in this study and also include from the general population.

\section{CONCLUSION}

The commonest most mental disorder among the Pakistani children was found to be Attention Deficit
Hyperactivity Disorder. A multi-center study with a larger sample size to estimate the prevalence of psychiatric disorders in Pakistani children is thus recommended. The findings of such a study would be paramount to informing future health policy for the significance of further developing mental health services in the health infrastructure of Pakistan.

\section{CONFLICT OF INTEREST}

This study has no conflict of interest to be declared by any author.

\section{REFERENCES}

1. Cautin RL, Lilienfeld SO. The Encyclopedia of Clinical Psychology, 5 Volume Set: John Wiley \& Sons; 2015 Avalibal at Internet. https: //www.wiley.com/en-us/exportProduct/pdf/ 9780470671276.

2. Sayers J. The world health report 2001-Mental health: new understanding, new hope. Bulletin World Health Organiza 2001; 79(45): 1085-87.

3. Xiaoli Y, Chao J, Wen P, Wenming X, Fang L, Ning L, et al. Prevalence of psychiatric disorders among children and adolescents in northeast China. PLoS One 2014; 9(10): e111223-25.

4. Richter LM, Daelmans B, Lombardi J. Investing in the foundation of sustainable development: pathways to scale up for early childhood development. Lancet 2017; 389(10064): 103-18.

5. Imran N, Azeem MW, Sattar A, Bhatti MR. Frequency of ICD-10 psychiatric diagnosis in children with intellectual disability in Lahore, Pakistan \& Caregivers Perspective. Pak J Med Scie 2015; 31(2): 285-88.

6. Mohammadi MR, Ahmadi N, Kamali K, Khaleghi A, Ahmadi A. Epidemiology of Psychiatric Disorders in Iranian Children and Adolescents (IRCAP) and Its Relationship with Social Capital, Life Style and Parents' Personality Disorders: Study Protocol. Iran J Psychiatr 2017; 12(1): 66-72.

7. Vicente B, Saldivia S, de la Barra F, Kohn R, Pihan R, Valdivia M, et al. Prevalence of child and adolescent mental disorders in Chile: a community epidemiological study. J Child Psychol Psychiatry 2012; 53(10): 1026-35.

8. Galan CA, Shaw DS, Dishion TJ, Wilson MN. Neighborhood deprivation during early childhood and conduct problems in middle childhood: mediation by aggressive response generation. J Abnormal Child Psychol 2017; 45(5): 935-38.

9. Qu Y, Jiang H, Zhang N, Wang D, Guo L. Prevalence of mental disorders in 6-16-year-old students in Sichuan province, China. Inter J Environmental Res Public Health 2015; 12(5): 5090-07.

10. Wichstrom L, Berg Nielsen TS, Angold A, Egger HL, Solheim E, Sveen TH. Prevalence of psychiatric disorders in preschoolers. J Child Psychol Psychiatry 2012; 53(6): 695-05.

11. In-Albon T, Zumsteg U, Müller D, Schneider S. Mental disorders in the pediatric setting-results of a Swiss survey. Swiss Medical weekly 2010; 140(25): 1-5.

12. Merikangas KR, Nakamura EF, Kessler RC. Epidemiology of mental disorders in children and adolescents. Dialogues Clin Neurosci 2009; 11(1): 7-20.

13. Nielsen LG, Rimvall MK, Clemmensen L. The predictive validity of the Strengths and Difficulties Questionnaire in preschool age to identify mental disorders in preadolescence. PLoS One 2019; 14(6): 65-67.

14. Skokauskas N, Fung D, Flaherty LT. Shaping the future of child and adolescent psychiatry. Child Adolesc Psychiatry Ment Health 2019; 13(12): 19-22. 
15. Thomson KC, Richardson CG, Gadermann AM, Emerson SD, Shoveller J, Guhn M. Association of Childhood Social-Emotional Functioning Profiles at School Entry With Early-Onset Mental Health Conditions. JAMA Netw Open 2019; 2(1): 34-35.

16. Mohammadi MR, Ahmadi N, Khaleghi A. Prevalence and Correlates of Psychiatric Disorders in a National Survey of Iranian Children and Adolescents. Iran J Psychiatr 2019; 14(1):
1-15.

17. Alice P, Melissa J, Pont-Reyes D, Phelan JC, Kirstin Painter, Bruce G. Depression: Causes and treatment. Link Soc Sci Med 2018; 216(14): 88-96.

18. Weich S, Araya R. International and regional variation in the prevalence of common mental disorders: do we need more surveys. British J Psychiatr 2004; 184(4): 289-90. 